\title{
Waiting for Recovery: The Canadian Labour Market in June 2020
}

STEPHEN R.G. JONES FABIAN LANGE W. CRAIG RIDDELL CASEY WARMAN 


\section{$\checkmark$ CIRANO Knowledge into action}

Center for Interuniversity Research and Analysis on Organizations

The purpose of the Working Papers is to disseminate the results of research conducted by CIRANO research members in order to solicit exchanges and comments. These reports are written in the style of scientific publications. The ideas and opinions expressed in these documents are solely those of the authors.

Les cahiers de la série scientifique visent à rendre accessibles les résultats des recherches effectuées par des chercheurs membres du CIRANO afin de susciter échanges et commentaires. Ces cahiers sont rédigés dans le style des publications scientifiques et n'engagent que leurs auteurs.

CIRANO is a private non-profit organization incorporated under the Quebec Companies Act. Its infrastructure and research activities are funded through fees paid by member organizations, an infrastructure grant from the government of Quebec, and grants and research mandates obtained by its research teams.

Le CIRANO est un organisme sans but lucratif constitué en vertu de la Loi des compagnies du Québec. Le financement de son infrastructure et de ses activités de recherche provient des cotisations de ses organisations-membres, d'une subvention d'infrastructure du gouvernement du Québec, de même que des subventions et mandats obtenus par ses équipes de recherche.

\section{CIRANO Partners - Les partenaires du CIRANO}

Corporate Partners - Partenaires corporatifs

Autorité des marchés financiers

Bank of Canada

Bell Canada

BMO Financial Group

Business Development Bank of Canada

Caisse de dépôt et placement du Québec

Desjardins Group

Énergir

Hydro-Québec

Innovation, Science and Economic Development Canada

Intact Financial Corporation

Manulife Canada

Ministère de l'Économie, de la Science et de l'Innovation

Ministère des finances du Québec

National Bank of Canada

Power Corporation of Canada

PSP Investments

Rio Tinto

Ville de Montréal

Academic Partners - Partenaires universitaires

Concordia University

École de technologie supérieure

École nationale d'administration publique

HEC Montréal

McGill University

National Institute for Scientific Research

Polytechnique Montréal

Université de Montréal

Université de Sherbrooke

Université du Québec

Université du Québec à Montréal

Université Laval

CIRANO collaborates with many centers and university research chairs; list available on its website. Le CIRANO collabore avec de nombreux centres et chaires de recherche universitaires dont on peut consulter la liste sur son site web.

(C) June 2020. Stephen R.G. Jones, Fabian Lange, W. Craig Riddell, Casey Warman. All rights reserved. Tous droits réservés. Short sections may be quoted without explicit permission, if full credit, including (C) notice, is given to the source. Reproduction partielle permise avec citation du document source, incluant la notice (C).

The observations and viewpoints expressed in this publication are the sole responsibility of the authors; they do not necessarily represent the positions of CIRANO or its partners. Les idées et les opinions émises dans cette publication sont sous l'unique responsabilité des auteurs et ne représentent pas nécessairement les positions du CIRANO ou de ses partenaires. 


\title{
Waiting for Recovery: The Canadian Labour Market in June 2020*
}

\author{
Stephen R.G. Jones `’, Fabian Lange ${ }^{\ddagger}$, W. Craig Riddell §, Casey Warman ${ }^{* *}$
}

\begin{abstract}
Résumé
The Canadian labour market is currently emerging from a holding pattern with un- usually high numbers in temporary (or "recall") unemployment, those "employed but absent from work" for unspecified reasons, or not in the labour force while waiting to be recalled. Two encouraging signs are evident. New postings of vacancies have recovered from $50 \%$ percent to about $80 \%$ of their pre-crisis level. Also, data suggest that the increase in employment in May 2020 is due to some of those waiting to be recalled re-entering employment. These patterns suggest that a reasonably quick re- bound of the labour market may be possible. Warning signs are that the shares of the unemployed without job attachment as well as those on recall engaged in job search are beginning to increase.
\end{abstract}

Keywords/Mots-clés: COVID-19, Vacancies, Unemployment, Employment

JEL Codes/Codes JEL: J21, J22, J23, J63

\footnotetext{
* We would like to thank ESDC for sharing the Job Bank data and Brendon Bernard at Indeed Canada (see https://www.hiringlab.org/en-ca/) for sharing the Indeed vacancy index. We also would like to thank Ronit Mukherji for able research assistance.

† McMaster University

$*$ McGill University and NBER and IZA and CIRANO

$\S$ University of British Columbia and IZA

** Dalhousie University and NBER
} 


\section{Introduction}

The epidemic spread of the Coronavirus in Spring 2020 and the ensuing shutdown of the economy have plunged Canada's labour market into crisis. Within weeks, employment dropped by $15 \%$ and hours worked by $32 \%$ (Lemieux et al., 2020). ${ }^{1}$ As noted elsewhere and as we document below, much of the employment decline resulted in a rapid increase in temporary layoff unemployment. At the same time, job matching in the open market - the forming of new employment relationships between previously unconnected job seekers and employers contracted sharply.

The length and the depth of the ensuing recession will to a large degree depend on both whether those laid off in March and April remain attached to the labour market and on how quickly hiring in the open market recovers. Should either fail, the increases in nonemployment could potentially take years to unwind.

This paper examines the state of the labour market in early summer 2020 with an eye towards two broad, interrelated questions. First, are there signs that hiring intentions on the open labour market are recovering? For example, do we observe firms beginning to be active in hiring beyond simply recalling workers previously put on furlough or temporary layoffs? Second, do those separated in March and April maintain their links to the labour market? Do they remain closely connected to their prior employers, maybe awaiting recall? How is search activity affected among the non-employed?

We rely on data from the Canadian Labour Force Survey (LFS) and from a set of online Job Boards to attempt to answer these questions three months into the COVID-19 crisis. $^{2}$

Traditionally, the process of hiring is conceived as one where individuals search for jobs and employers search for workers. The dynamics of the labour market in June 2020 have largely become disconnected from this process. Large parts of the workforce are waiting

\footnotetext{
${ }^{1}$ Lemieux et al. (2020) estimate the impact of the pandemic on employment and hours of work relative to a no-COVID-19 counterfactual.

${ }^{2}$ The vacancy data spans January $5^{t h}$ to June $10^{t h}, 2020$. We measure weeks from Wednesday - Tuesday, following the convention employed by Stata. The LFS data includes the May data released in early June 2020 .
} 
to rejoin their employers and how quickly they are recalled will determine the dynamics of unemployment in the next few months. In the background however, the traditional matching process is still taking taking place. We show evidence that vacancy postings in Canada have recovered to about $80 \%$ of their pre-crisis level. And, among the non-employed there are signs that the number of individuals searching for jobs is increasing. This duality in the labour market between temporary separations and the open labour market will likely persist through the Summer and Fall.

We rely heavily on the Labour Force Survey (LFS), a data set that requires little introduction. In addition, we use data on vacancies provided to us by ESDC. We use these data together with data from Indeed Canada to measure the dynamics of labour demand in Section 2. Section 3 presents how employment, unemployment, and non-participation (NILF) evolved over the last few months. We also explore more detailed information on subgroups within these categories to explore which parts of the work-force are temporarily or perhaps permanently separated from their former places of work. Sections 4 and 5 contain supplemental evidence on heterogeneity in impacts across industries and occupations as well as provinces.

\section{Vacancy Postings during the COVID-19 Crisis}

\subsection{Job Bank data}

The vacancy data was provided to us by Employment and Social Development Canada (ESDC) and contains vacancies posted on the Job Bank, a job board maintained by ESDC, as well as vacancies posted by external providers. The external providers include provincial job boards maintained by Employment Quebec, Saskjobs, and WorkBC as well as some

maintained by private job boards such as Monster.com, Careerbeacon, Jobillico, PSC, and ZipRecruiter. In the following we will refer to these data as the "Job Bank."

The disadvantage of the Job Bank data is that it is clearly not a representative sample of 
job openings in Canada, such as for instance is provided by Statistics Canada's Job Vacancy and Wage Survey (JVWS). As we document in the online appendix, the distribution of postings across provinces is very uneven. To account for this, we reweight the data to match the population distribution across provinces estimated using 2016 Census data. More worrisome still is that between 2015 and 2018, the time-series of postings according to the Job Bank data deviates substantially from the time-series obtained from the JVWS.

The crucial advantage of the Job Bank data is that they provide weekly, up-to-date information on vacancies posted. In contrast, the JVWS is a quarterly survey published only with long lags. ${ }^{3}$

However, as we are concerned about the the degree to which the Job Bank data is representative, we have obtained an alternative index from Indeed Canada, a private online job board and job search company. This alternative index is based on postings directly on Indeed as well as postings retrieved by Indeed from the net and in the Appendix we show this index for the period between February $1^{\text {st }}$ and June $5^{\text {th }}$. This evidence is consistent with our finding from Job Bank data that new posted vacancies declined by about $50 \%$ between late March and early April and have since increased substantially, although the increase in the Indeed data is less pronounced.

\subsection{Aggregate Trends in Vacancy Postings}

Figure 1 shows the evolution of new vacancies posted on Job Bank between January $5^{\text {th }}$ and June $9^{t h}, 2020$. Postings declined rapidly to about 50\% of the level prior to March $15^{\text {th }}$. However, since the beginning of April, vacancies posted on the Job Bank have staged a remarkable comeback. The most recent data (referring to the week ending on June $9^{\text {th }}$ ) suggests that vacancies rebounded to roughly $80 \%$ of the level attained in the weeks prior to the COVID-19 crisis. $^{4}$

\footnotetext{
${ }^{3}$ The most recent available data is for the $3^{\text {rd }}$ quarter of 2019. This makes it ill-suited for gauging which direction the labour market is currently heading in.

${ }^{4}$ The Indeed data in the Appendix suggests that the decline in vacancies in the U.S. was not quite as severe as the decline observed in Canada, but likewise there was less of a recovery in vacancies in the U.S.
} 
Figure 1: Total Job Postings January-June 2020

on Job Bank and External Sources

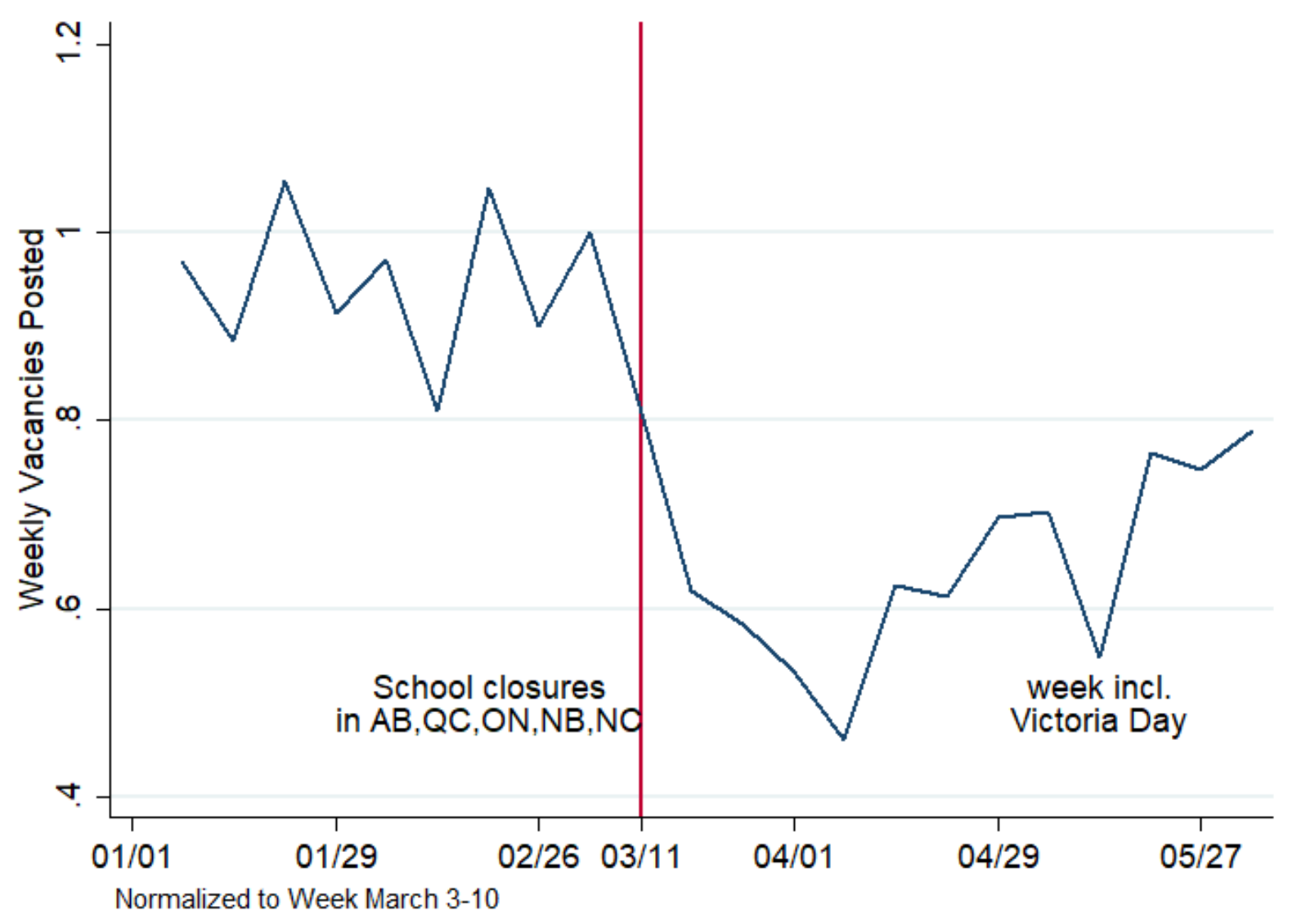

Note: Based on Job Bank data provided by ESDC. Weekends omitted. Weighted to distribution across Provinces. Weeks are defined to start on Wednesdays following the Stata convention.

\section{Employment, Unemployment and Labour Force Par- ticipation}

We now turn to the question of how closely attached to the labour market those who lost employment in the Spring of 2020 remain. We rely on the public use version of the Labour Force Survey from January 2018 to May 2020. This is a nationally representative survey of in April and May. 
the Canadian population. We restrict the sample to ages 25 to $64 .^{5}$

To begin, we consider the standard labour force states employment E, unemployment U, and non-participation NILF. We note, and will return to this later, that the standard categories have some ambiguities. These "grey areas" are even more pronounced at present - in part because of the nature of the COVID-19 downturn and also to some extent due to policy responses.

Figure 2 plots employment and unemployment as a fraction of the population, and the non-participation rate (1 - labour force participation rate) monthly from January 2018 to May 2020. ${ }^{6}$

Several key points are evident. The employment rate declines sharply by approximately 10 percentage points from February to April before rebounding modestly in May. As expected, a significant fraction of the employment loss is reflected in higher unemployment hence the steep rise in U/POP over the February to May period. However, much of the employment decline also shows up in the form of a sharp reduction in labour force participation between February and April. For example, the March LFS reported that more than one million workers lost jobs in the previous month (Statistics Canada, The Daily, March 2020), yet unemployment increased by less than 450,000. According to the standard division between unemployment and non-participation (NILF) which is based on reported job search, more than one-half of these job losers withdrew from the workforce and a bit less than one-half increased the stock of the unemployed. ${ }^{7}$

We next illustrate and discuss the margins between employment and non-employment and, within the non-employed, between unemployment and non-participation. Our objective is both to provide a broad picture of the nature of the COVID-19 downturn in the labour

\footnotetext{
${ }^{5}$ As was seen with the U.S. Current Population Survey, the LFS experienced a decline in the response rate with the onset of COVID-19. In March 2020, the face-to-face interviews were replaced by telephone interviews. The unweighted sample size dropped from around 100 thousand to around 90 thousand.

${ }^{6}$ LFS data in this paper are not seasonally adjusted.

${ }^{7}$ With two exceptions, to be classified as unemployed LFS respondents must be available for work and report job search. The exceptions are temporary layoffs - those who either have a definite date to return to work or an indication from their employer that they will be recalled - and those who have a job to start within the next 4 weeks, termed "future job starts."
} 
Figure 2: Labour Force Shares of Population

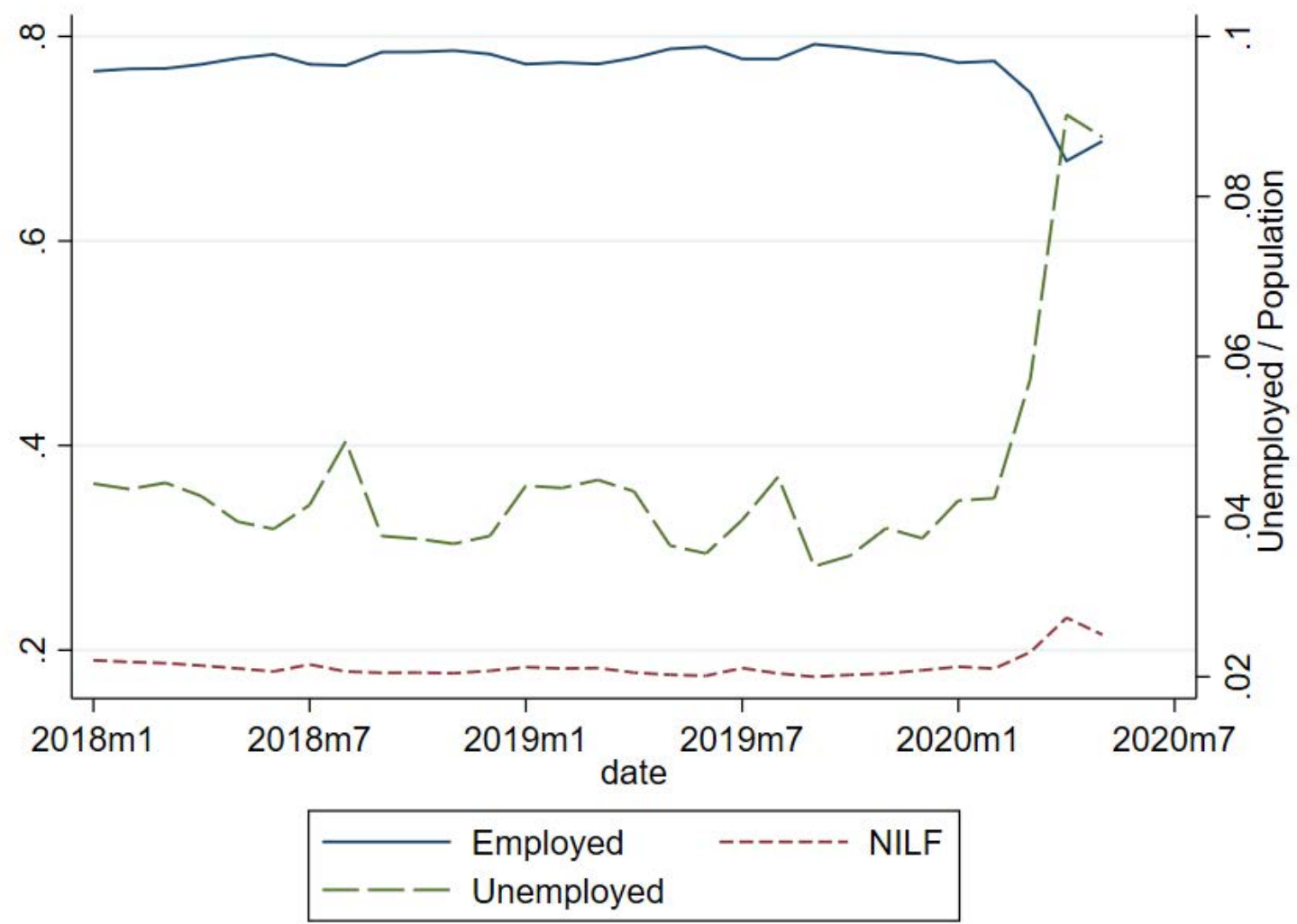

Note: LH scale for E/POP and NILF/POP; RH scale for U/POP.

market and to assess the extent to which the non-employed want to return to work. The principal findings are:

- The decline in measured employment vastly understates the decline in work performed during April and May 2020. An additional 9-10 percentage points of the population are now reporting being absent from work and most of these are not being paid by their employers.

- Most of the unemployed are not traditional job seekers but rather are waiting to be recalled to their former jobs. The majority of those awaiting recall are not currently searching for work. Since March, the number of unemployed that is seeking new 
employment has increased only by about 1 percentage point.

- Among those not-in-the-labour force, there has been a marked rise in those displaying Marginal Attachment to the labour force, reporting a desire for work but not currently engaged in job search.

\subsection{Employment Rates}

The margin between employment and non-employment is usually viewed as being well defined. However, during the COVID-19 downturn this margin has become less well defined in that a significant share of workers reported being absent from work for unspecified reasons. Many of these have not continued to be paid during this period.

Figure 3 shows the composition of the employed (as a proportion of the population) that report being absent for the full week from work for the period since January 2018. In normal times, about $5-6 \%$ of the population is absent from work. The main reasons offered to explain these absences are being on vacation, illness/disability, and personal/family reasons. Not surprisingly, there is a strong seasonal pattern in vacations with many employees being on vacation in July and August and a smaller spike in March during the school break period. The 'Other' category is usually small. By contrast, we saw huge increases in those reporting absence for 'Other reasons' in March and April followed by a modest decline in May. ${ }^{8}$ The question is: are these individuals any different from those who report being on recall and are categorized as unemployed on temporary layoff?

One clue to answer this question is to ask whether those absent from work were paid or not. This information is only available for full-week absences and also excludes self-employed unincorporated workers. Figure 4 shows that initially in March, around half the full-week

\footnotetext{
${ }^{8}$ Similar behaviour is evident in the U.S. CPS. Indeed, in its May release (https://www.bls.gov/news.release/empsit.nr0.htm) the BLS drew attention to a "misclassification error" in its data and reported the official unemployment rate and the rate including this "Employed absent for other reasons' group. Inclusion of this group raised the U.S. unemployment rate by a striking three percentage points from $13.3 \%$ to $16.3 \%$.
} 
Figure 3: Share of Employed Full Week Absent from Work by Reason

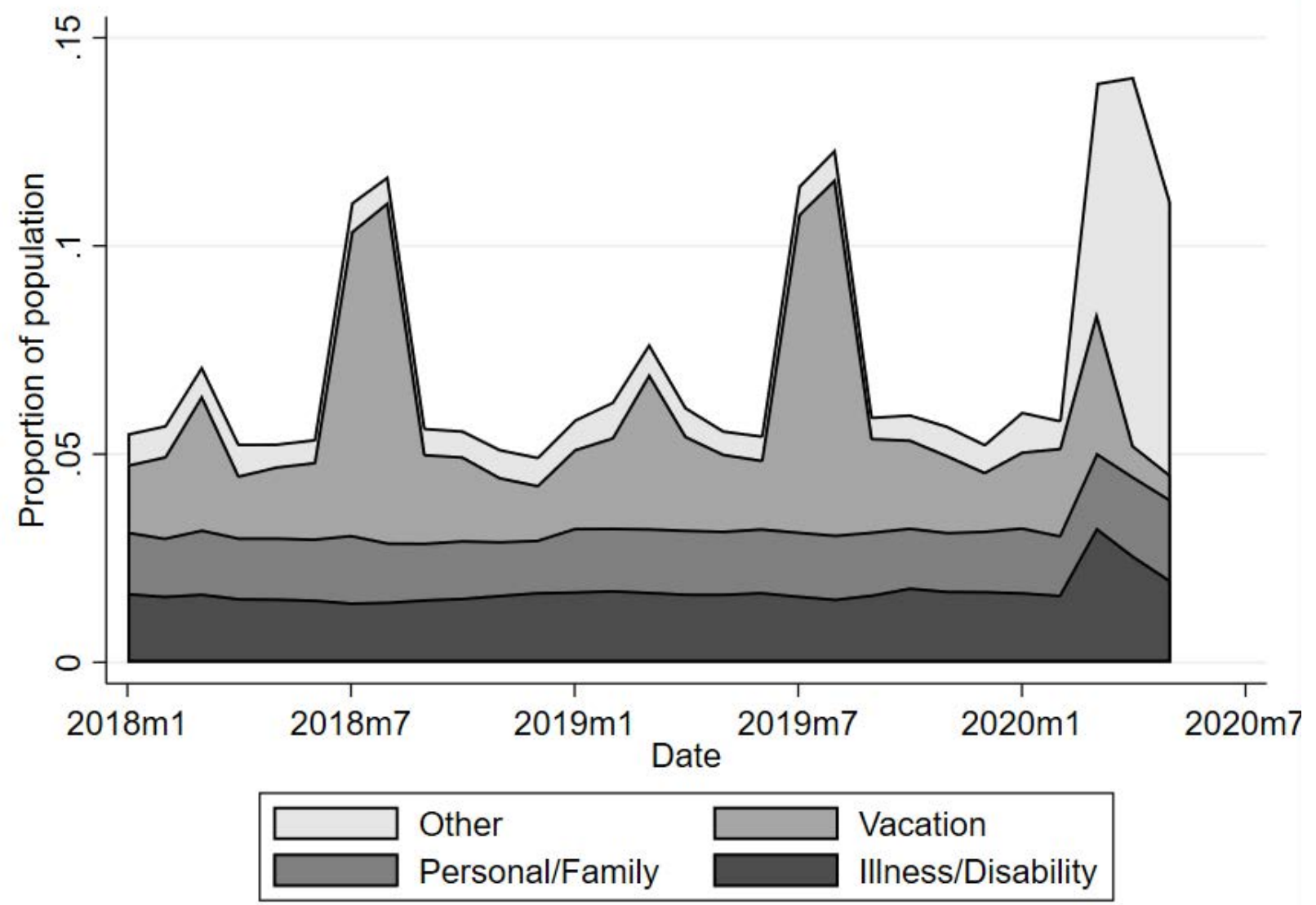

Note: Authors' calculations based on the LFS. "Other" includes: no work available, seasonal business, strike/lockout, and other related reasons. "Personal/family" includes: caring for own children, elderly relative, maternity/paternity leave and other related personal/family reasons. Calculated as share of population ages $25-64$.

absences were paid and the other half were not paid. ${ }^{9}$ However, by the reference period in May, paid absences had returned to pre-COVID-19 levels, while unpaid absences continued to be unusually elevated.

To summarize, in addition to the decline in the employment rate of close to 8 percentage points of the working age population (Figure 2), the share of those absent from work increased by an additional 9-10 percentage points (Figure 3), most of whom are not being paid during

\footnotetext{
${ }^{9}$ See Figure A3 for the same results restricted to those absent for "Other" reasons.
} 


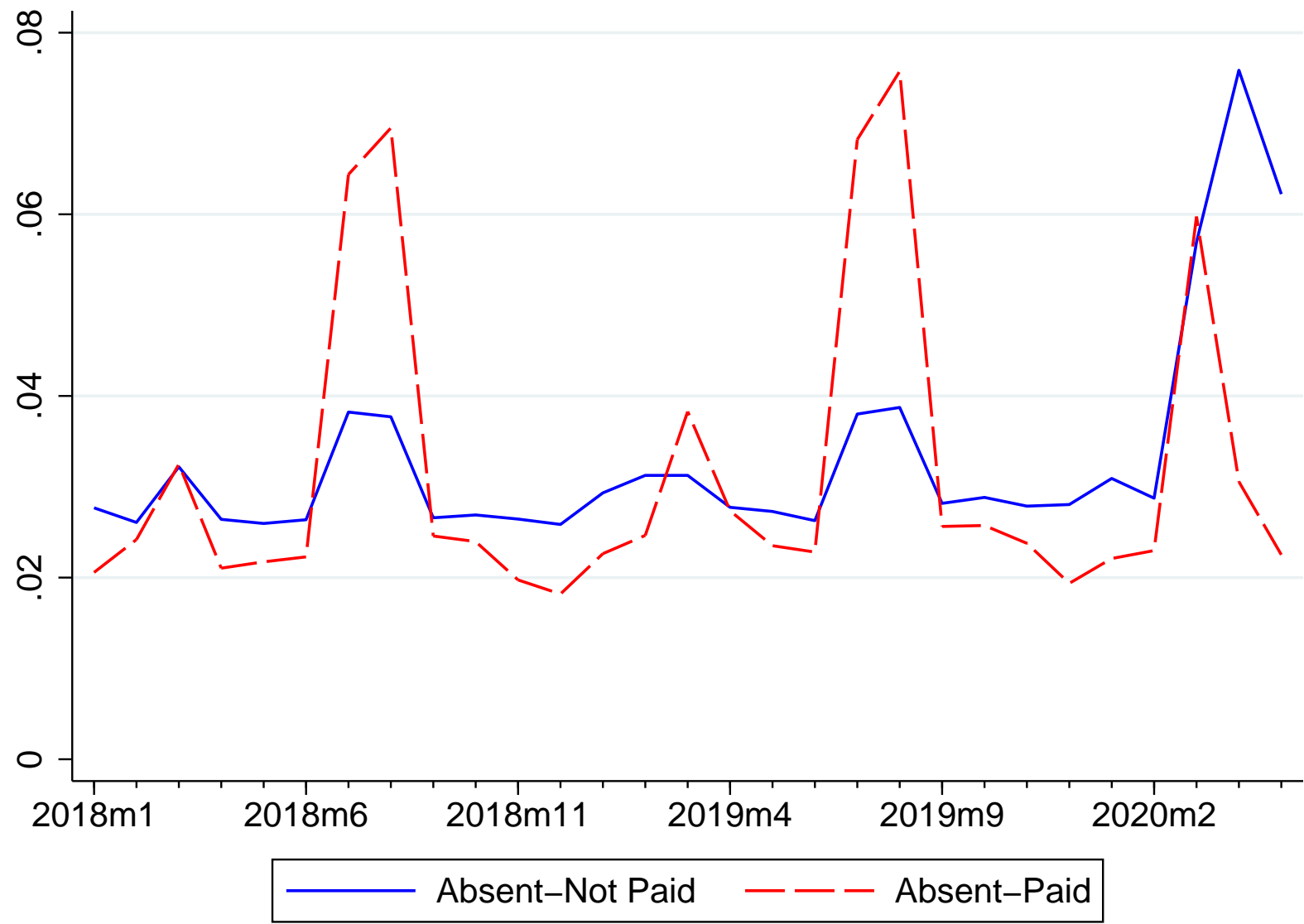

Note: Authors' calculations based on the LFS. The paid for time off information is not available for self-employed unincorporated workers. "Other" includes: no work available, seasonal business, strike/lockout, and other related reasons. "Personal/family" includes: caring for own children, elderly relative, maternity/paternity leave and other related personal/family reasons. Calculated as share of population ages 25-64.

their absence (Figure 4). ${ }^{10}$ There is thus a very sizeable part of the workforce that is not productive, that is not being paid, but that still reports being attached to their employers. This group should, we believe, be thought of as vulnerable to more formal separations from their employers if the economic downturn deepens and/or lengthens.

\footnotetext{
${ }^{10}$ Lemieux et al. (2020) report that employment excluding those absent from work declined by 15 percentage points in March and April 2020. We refer the reader to this paper for a detailed analysis of the heterogeneity in the decline in employment during the immediate onset of the COVID-19 crisis.
} 


\subsection{Unemployment Rates}

In addition to complicating the employment/non-employment margin, the upheavals of the COVID-19 era have generated dramatic changes in how unemployment is conceptualized, calling into question standard modes of labour market classification. While official statistics show an unemployment rate of $13.7 \%$ in May 2020, down slightly from April, the composition of this unemployment is in many ways the larger story.

Figure 5: Categories under Unemployed

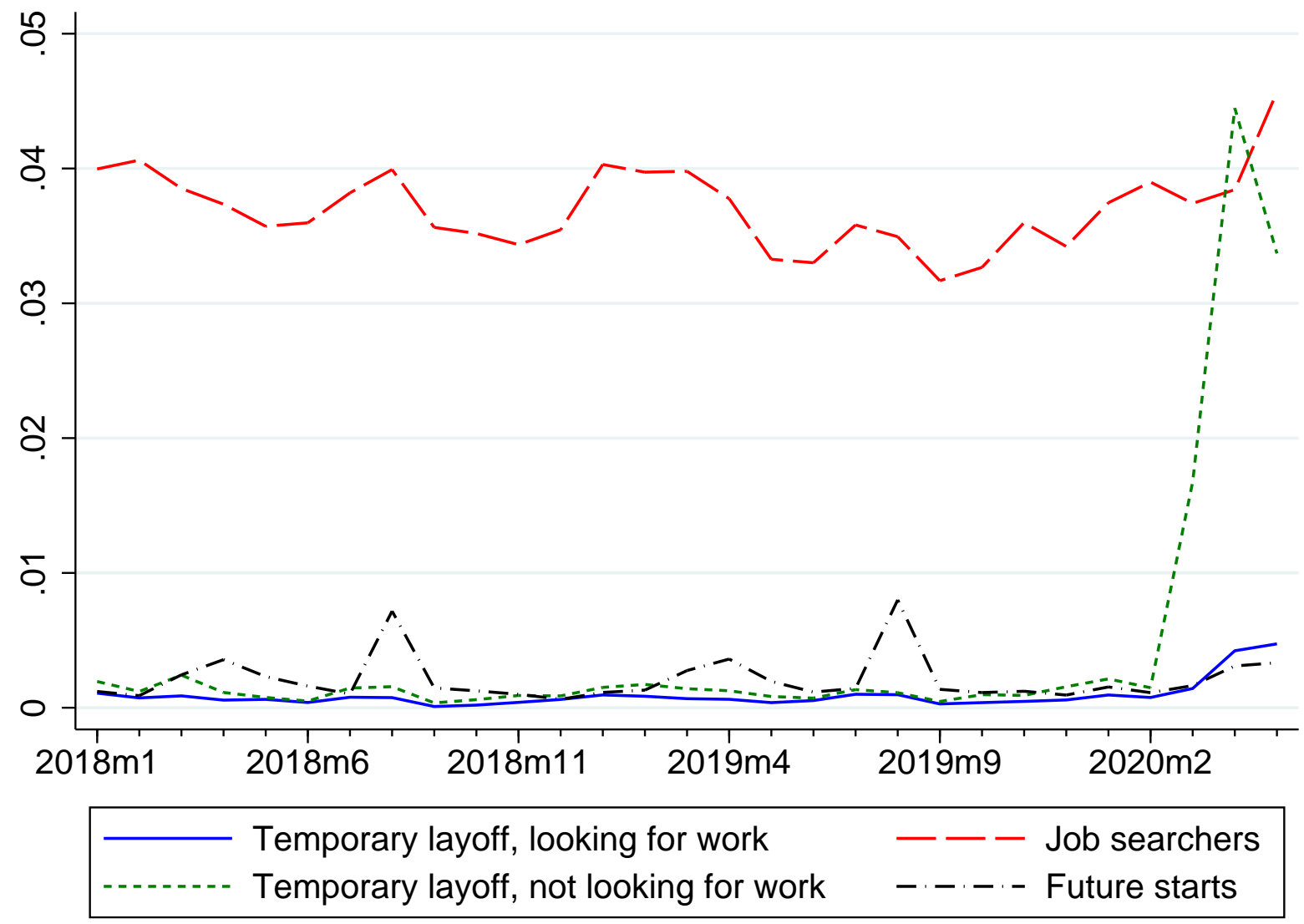

Note: Authors' calculations based on the LFS. Calculated as share of population ages 25-64.

In normal times, the vast majority of official unemployment is made up of job searchers who are currently available for work, with both temporary layoffs (who must be available 
for work but do not have to report job search) and short-term future job starts (within the next four weeks) being very small in comparison. The levels for 2018 and 2019 in the preCOVID-19 period in Figure 5 illustrate the relative magnitudes of these subgroups within unemployed that are usually observed.

Since March 2020, however, there has been a dramatic rise in unemployment owing to temporary layoff such that this component of unemployment is now as large as the group of job searchers (Figure 5). We see in this figure that most of this increase in temporary layoffs are not searching for jobs. Overall, we believe that this means that among those unemployed a much higher proportion than ever before maintains close ties with a previous employer. We also note that the entire decline in unemployment from April to May 2020 comes from a reduction of the temporary unemployed that are not currently looking for work, plausibly as a consequence of first efforts to reopen the economy, especially in Québec (see Section 5).

The data also shows that search unemployment is increasing, even if substantially less rapidly than unemployment amongst those not engaged in search. Adding together those on temporary layoff that are currently also looking for jobs and regular job searchers, we obtain that the fraction looking for work has risen by about one percentage point between March and May. This is likely because (i) the decline in labour demand (Section 2) makes it harder for job searchers to find employment and (ii) some of those temporarily unemployed start separating from their former employment. These statistics on job seekers are, we believe, particularly noteworthy and bear following closely in the next months to gauge how much longer-lasting damage is being inflicted on the labour market.

\subsection{Marginal Attachment and NILF}

Past labour market research on the heterogeneity of the NILF group has highlighted the importance of the "want work" question, with individuals professing a desire to work being a distinct group from the balance of non-participants. Members of this group, termed the marginally attached, display subsequent movement into employment at transition rates that 
are typically not much below the average rate for the officially unemployed (Jones and Riddell, 1999). As such, they represent a group that exhibits substantial attachment to the labour market. Moreover, a body of work shows that such marginal attachment behaviour is found in both Canada and the U.S. (e.g., Jones and Riddell (2019)), as well as in a range of other economies.

Figure 6: Not in the Labour Force: Marginally Attached and NILF without Marginally Attached

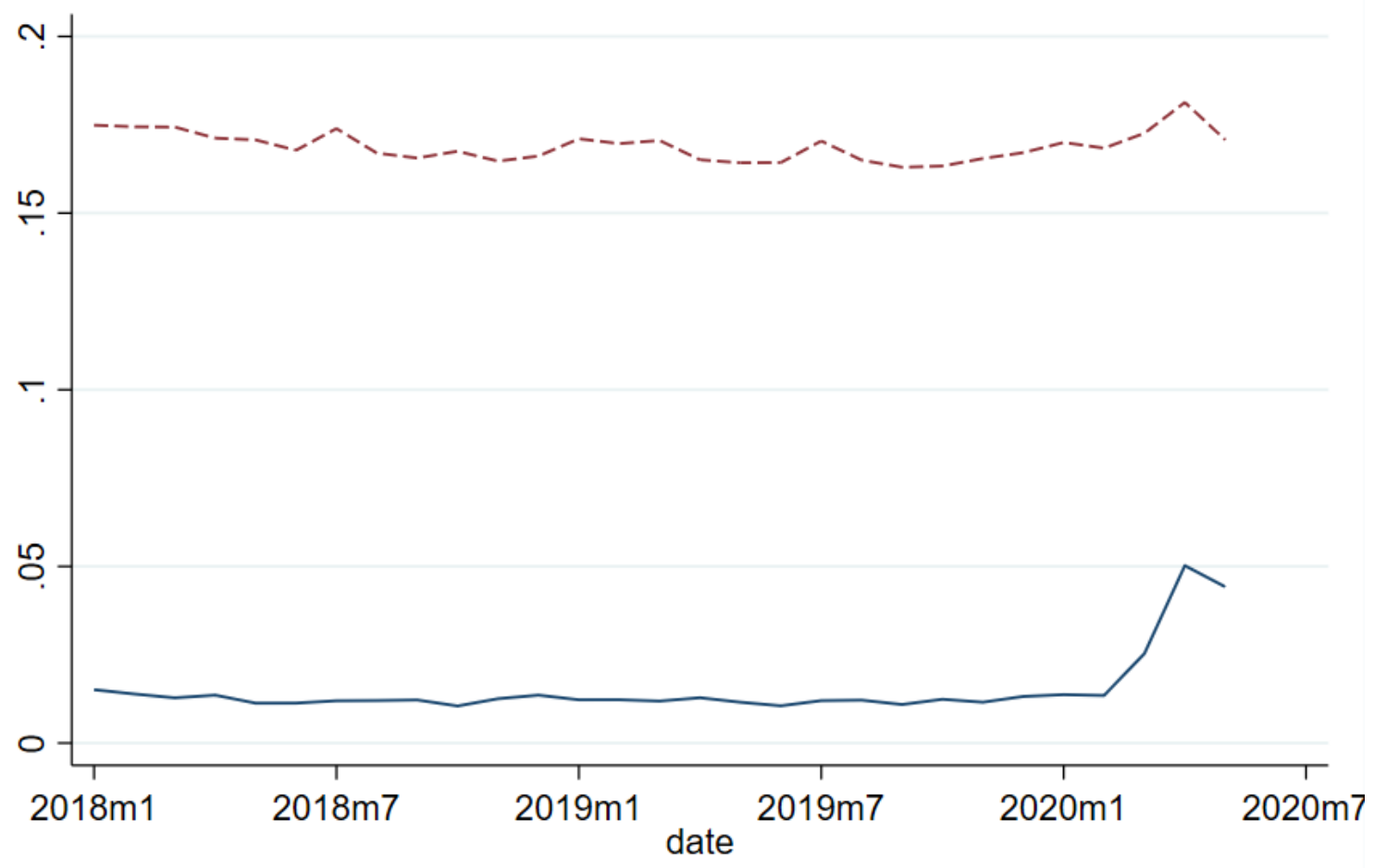

\section{Marginally Attached ------- NILF without Marginally Attached}

Note: Authors' calculations based on the LFS. Calculated as share of population ages 25-64.

In the COVID-19 era, Figure 6 shows the huge increase in share of Marginal Attachment in NILF. In the February to April 2020 period, the relative importance of Marginal Attachment rose markedly, with about 1.5 million individuals exhibiting that level of attachment in April (official unemployment was 2.4 million in that month). The small signs 
of labour market response to the relaxation of restrictions are also evident in the Marginal Attachment series in Figure 6, with the drop in May paralleling the dip in temporary layoff unemployment seen in Figure 5 above.

Among the Marginally Attached, Figure 7 shows a substantial compositional change, analogous to the change in the composition of official unemployment seen in Figure 5. The Marginally Attached can be classified according to the reason they give for not searching, although they report a desire for work, and the resulting classification includes "discouraged workers" (who report a belief that no work is available), those not searching for personal reasons and those "waiting" for replies to past job search efforts or recall to a former job. Evidence (Jones and Riddell, 1999) suggests that, at least in normal times, the "waiting" sub-group displayed the closest degree of labour market attachment.

Since February 2020, the dramatic composition change in Marginal Attachment has been largely due to growth in those awaiting recall or those NILF for "other reasons". These two categories account for approximately 4 percentage points of the total increase in those Marginally Attached. In addition, there has been a clear rise in the discouraged worker group, although quantitatively it remains a small part of the Marginal total.

Overall, these data show that a substantial fraction of the increase in NILF consists of individuals that are on recall and waiting to be rehired from their former employers. We do not know how many among the Marginally Attached for "other reasons" are permanently separated from their employers and how many should be thought of as waiting for being rehired. While we do not have direct evidence, we suspect that the availability of child care and the timing of school re-openings may have important effects on the composition of this Marginal Attached group within NILF. 
Figure 7: Categories under Marginally Attached

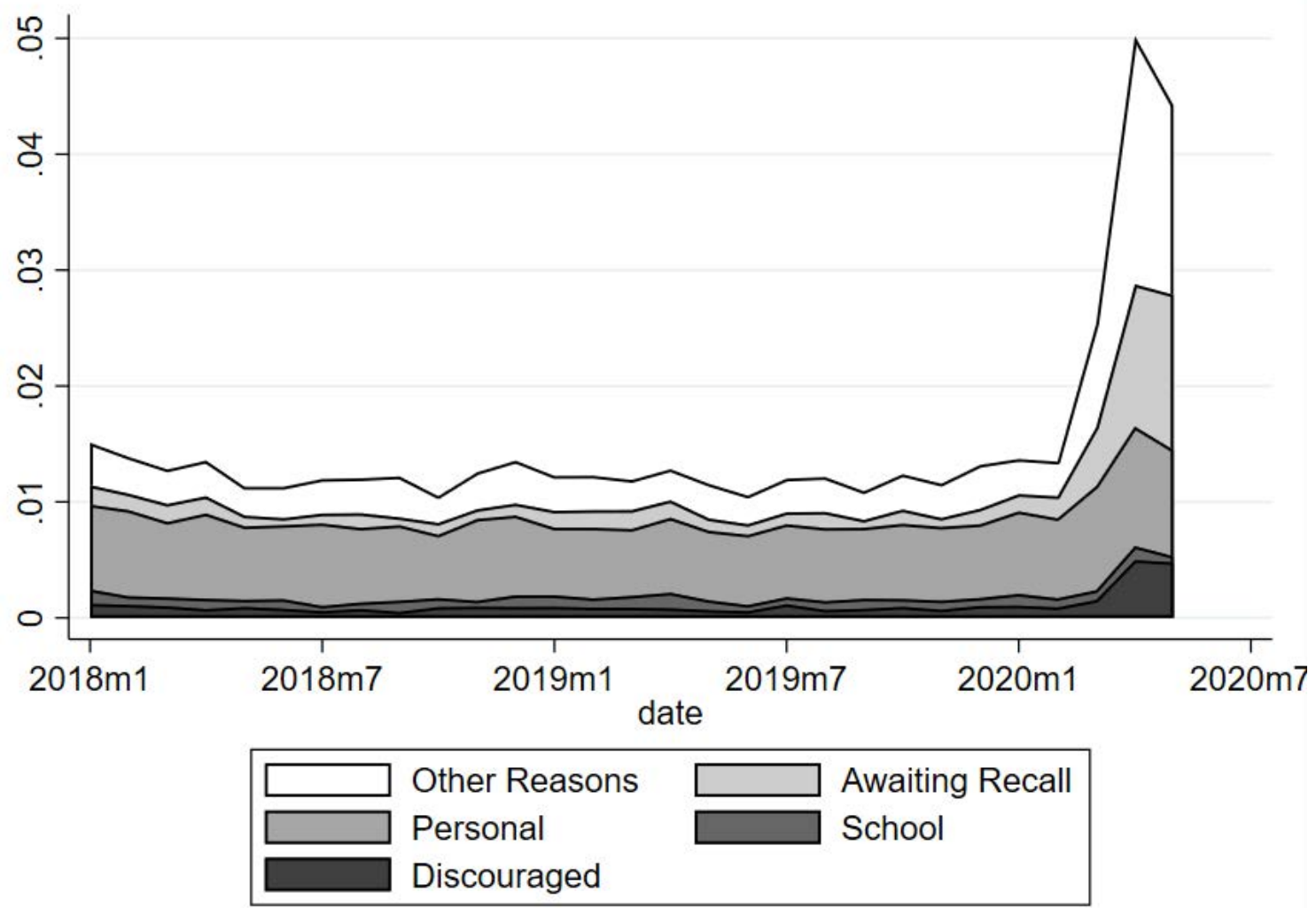

Note: Authors' calculations based on the LFS. Calculated as share of population ages 25-64. Categories are stacked, height represents monthly cumulative total.

\section{Essential and Non-essential Industries and Work from Home}

Occupations differ in the ability of workers to perform work from home rather than on-site. Occupations that allowed working from home have, to a degree, shielded workers from job loss. For example, in the U.S., Kahn et al. (2020) show that initial unemployment claims increased by more in occupations amenable to work-from-home. However, Kahn et al. (2020) also found that vacancy postings declined by more in occupations that could be performed 
from home rather than required being on-site. ${ }^{11}$

In this Section, we explore to what extent labour demand (measured by vacancies) varied across occupations by whether they could be performed from home or not, and by whether the occupations were in the health sector. We rely on the Dingel and Neiman (2020) score (DNscore hereafter) to determine the ability to work-from-home. Dingel and Neiman (2020) use O*NET data to assign to each occupation a score varying between 0 and 1 that measures the ability to work from home in this occupation. For the Job Bank data, we map the DN-score onto the 4-digit NOC system at our disposal and classify an occupation to work-from-home if the score is above 0.5. ${ }^{12}$ For the LFS, unfortunately, the public use version only provides 2-digit NOC codes. We therefore make use of the detailed NOC counts from the 2016 Census as weights to account for the relative size of each 4-digit NOC within a 2-digit NOC category.

Looking first at the Job Bank data, Figure 8 shows that health follows its own patterns in that the decline in vacancies was less pronounced in the immediate aftermath and that current rates of vacancy posting are running at and above those seen prior to the mid-March.

The ability to work-from-home, however, has no impact on labor demand as measured by vacancy postings. For both categories we see that demand declined by about $50 \%$ in the first 4 weeks of the crisis with a recovery to close to $80 \%$ in recent weeks. We interpret this as evidence that the deterioration of labour demand in March and early April was broad and driven by factors beyond the immediate ability to perform the work. We also observe that the recovery in postings since mid-April has been similarly broad.

In Figure 9, we see that non-employment has increased (top panel, short dashes) by about 10 percentage points in the age-group 25-64. Much of this increase comes from a decline in employment in occupations that are not amenable to work-from-home in nonessential industries. However, there are sizable declines in other industries groups as well. In

\footnotetext{
${ }^{11}$ They exclude health and essential retail, mostly grocery stores, from occupations that require work on-site.

${ }^{12}$ Approximately $0.35 \%$ of vacancies in the Job Bank data did not have a valid NOC code. We exclude these vacancies from the analysis. Most occupations have a DN score close to either 0 or 1 , so that our results are robust the choice of the exact cut-off on the DN scale to determine whether an occupation can be performed from home. We show the distribution of the DN-score in the appendix.
} 
Figure 8: Vacancy Postings by Ability to Work-from-Home

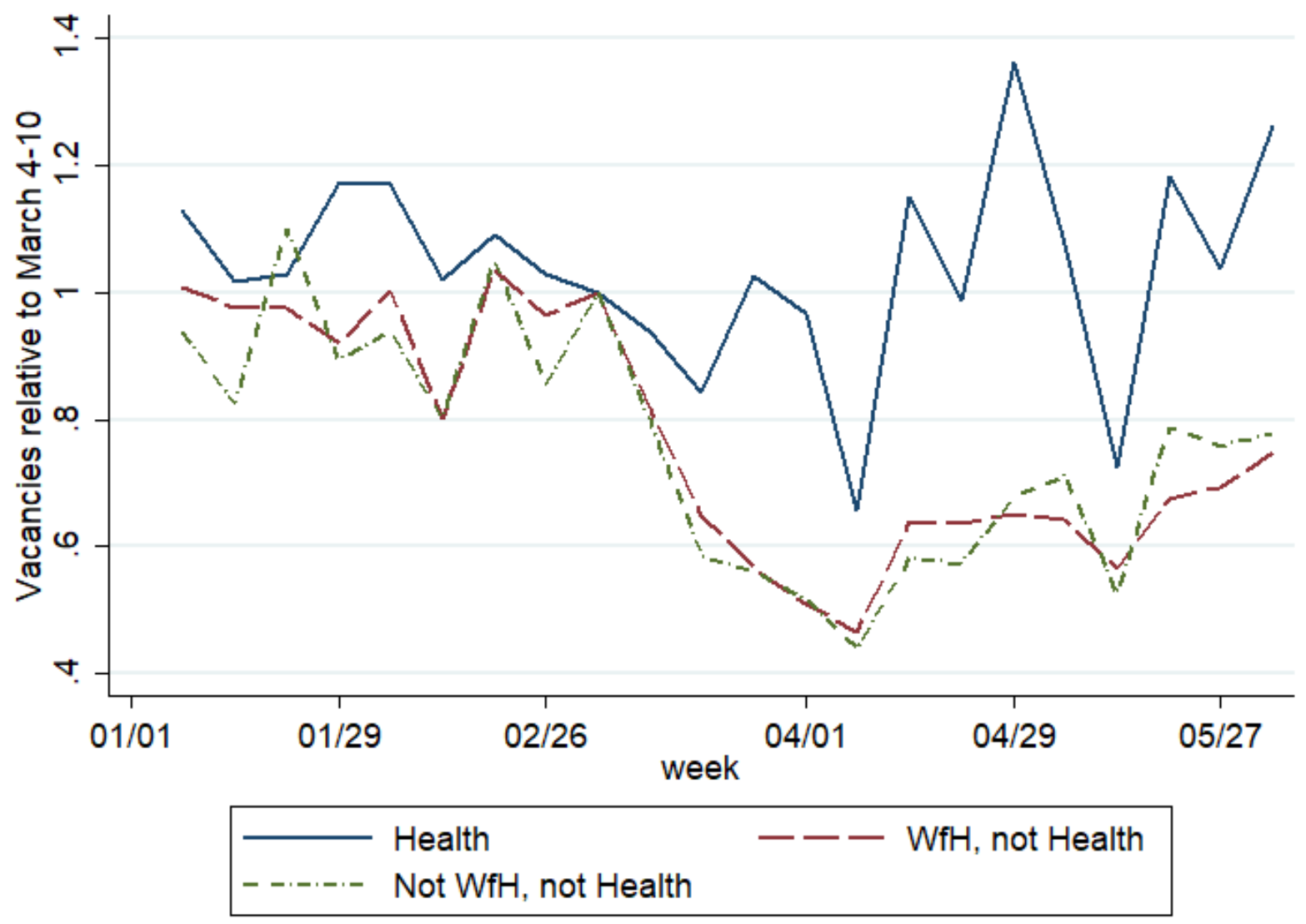

Note: The graph shows the ratio of vacancy posted in health (NOC-Digit 3) as well as by ability to work from home (Dingel-Neiman>0.5) Normalized to the week of March 4-10, 2020.

particular, there is a large percentage point decline in employment in occupations capable of work-from-home in non-essential industries. Overall, we see that only work-from-home, essential and health did not see their employment fall considerably.

In Figure 10, we further break up the absent category where we combine information on whether or not the job could be done from home, whether the job is in the Health sector and whether the job is categorized as essential or non-essential. All jobs find a large increase of those that are absent, but again, as is seen with the overall values in Figure 3, the increase is mostly concentrated in the "Other" category. This is particularly pronounced for the not 
Figure 9: Share of Employed by Health/Work from Home/Not work from Home $\times$ Essential/Non-Essential Worker

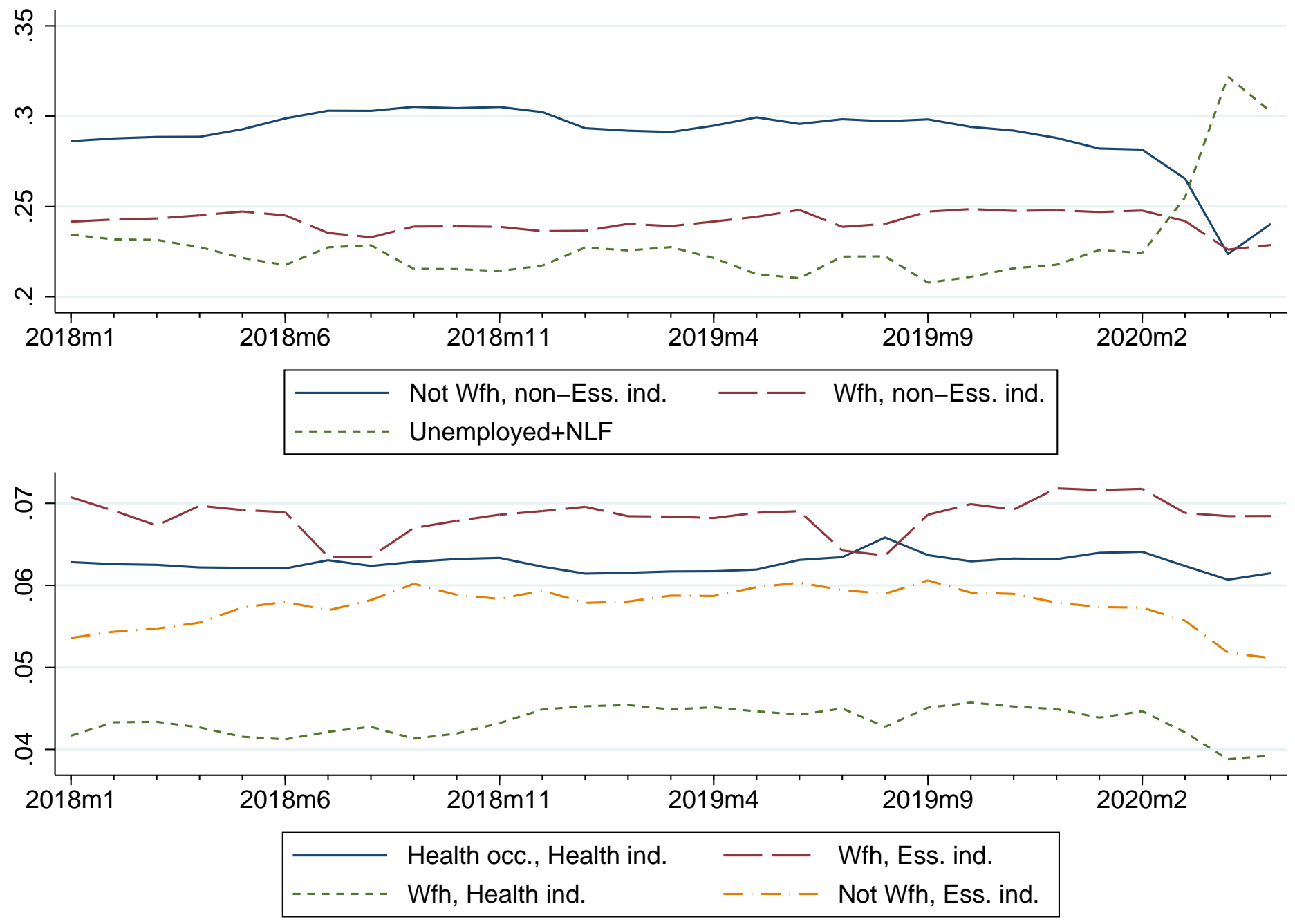

Note: Authors' calculations based on the LFS. Calculated as share of population ages 25-64.

work-from-home in non-essential industries, who make up almost half of the overall increase in absent from work seen in Figure 3. 
Figure 10: Breakdown of Absent category by Occupation/Industry

Not Wfh, non-Ess. ind.

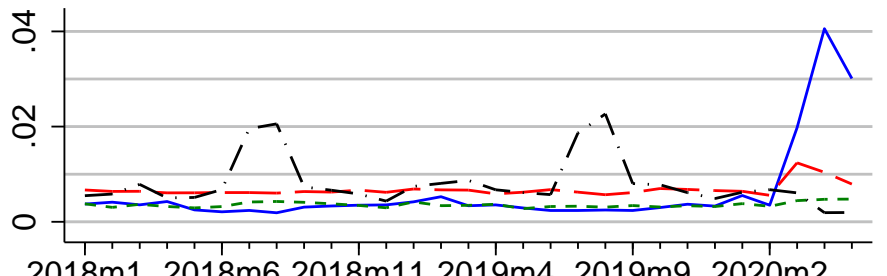

$2018 \mathrm{~m} 12018 \mathrm{~m} 62018 \mathrm{~m} 112019 \mathrm{~m} 42019 \mathrm{~m} 92020 \mathrm{~m} 2$

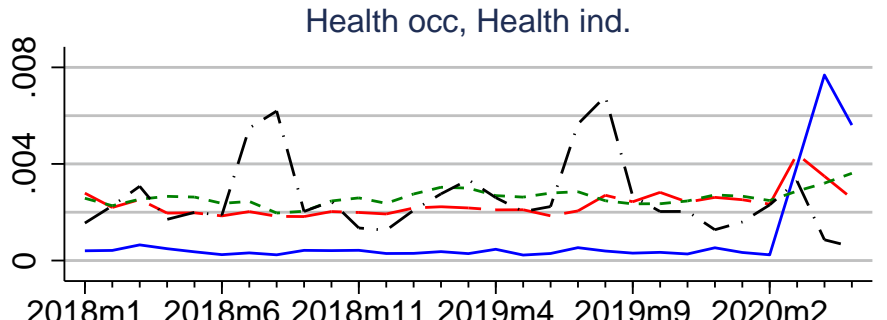

Wfh, Health ind.

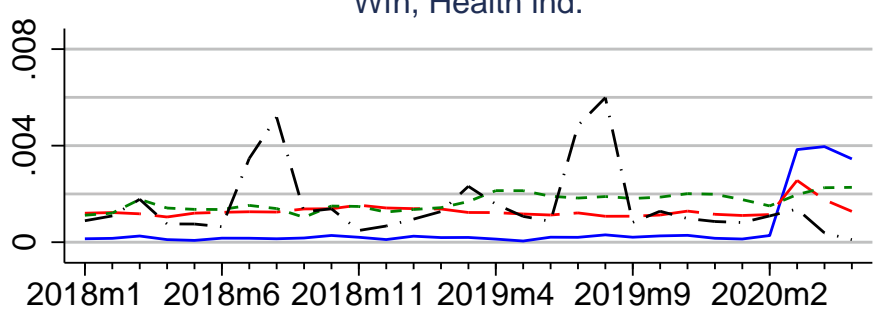

Wfh, non-Ess. ind.

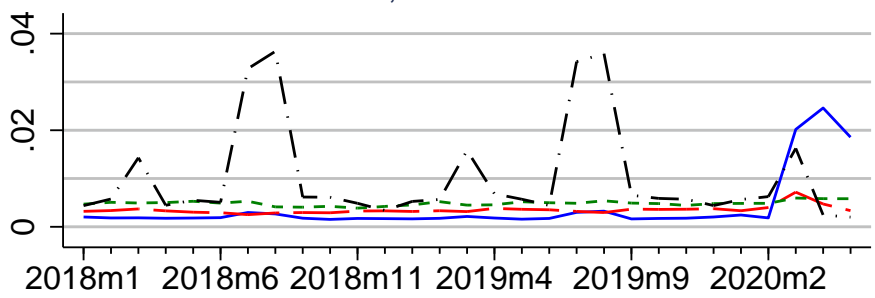

Wfh, Ess. ind.

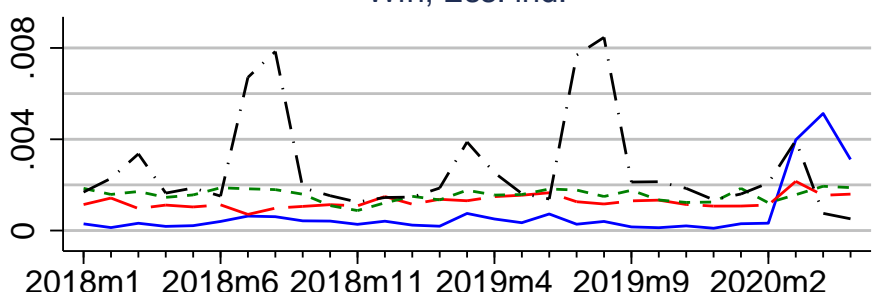

Not Wfh, Ess. ind.

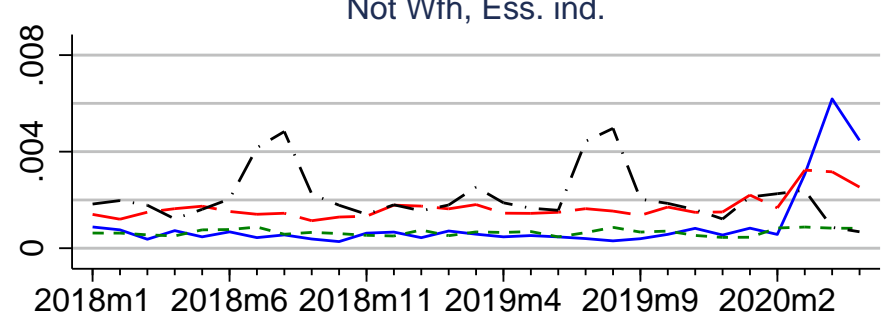

Note: Authors' calculations based on the LFS. "Other" includes: no work available, seasonal business, strike/lockout, and other related reasons. "Personal/family" includes: caring for own children, elderly relative, maternity/paternity leave and other related personal/family reasons. Calculated as share of population ages $25-64$.

\section{Province Level Differences}

Our final breakdown examines the variation across provinces and time. First, looking at the vacancy postings from the Job Bank data, Table 1 shows the decline across 3 week periods 
Table 1: Ratio of Vacancies Prior and Post March $15^{\text {th }}$, by Province

\begin{tabular}{lc} 
Province & $\begin{array}{c}\text { Post- / Pre-March } 15^{\text {th }} \\
\text { Vacancies }\end{array}$ \\
\hline Newfoundland and Labrador & 0.48 \\
Prince Edward Island & 0.49 \\
Nova Scotia & 0.61 \\
New Brunswick & 0.48 \\
Québec & 0.56 \\
Ontario & 0.64 \\
Manitoba & 0.54 \\
Saskatchewan & 0.51 \\
Alberta & 0.65 \\
British Columbia & 0.65 \\
Northern Canada & 0.44 \\
\hline Total & 0.55
\end{tabular}

Note: Authors' calculations using Job Bank Data.

before and after the pivotal March $15^{\text {th }}$. This Table shows that the decline in vacancy postings was broad based and of roughly similar magnitude across Canada. Among the larger provinces, the decline was more pronounced in Québec where vacancies declined to about $56 \%$ of the pre-period, whereas vacancies in British Columbia, Alberta, and Ontario declined by a little more than about one-third.

Québec also stands out in that the number of new vacancies posted has recovered more rapidly in Québec than in the other provinces. Figure 11 shows vacancies posted on the Job Bank in Québec compared with the other three most populous provinces. In Québec the recovery in vacancies began earlier and was substantially larger than in the other provinces. Figure 12 illustrates how employment varied across the same provinces. We find that the decline in employment is roughly the same order of magnitude in these four provinces, although it is slightly larger in Québec. However, employment also recovers more rapidly in Québec than in Alberta, Ontario, or British Columbia.

While Figure 12 highlights the large drop in employment across the provinces, we know 
Figure 11: Vacancy Postings across the 4 Largest Provinces

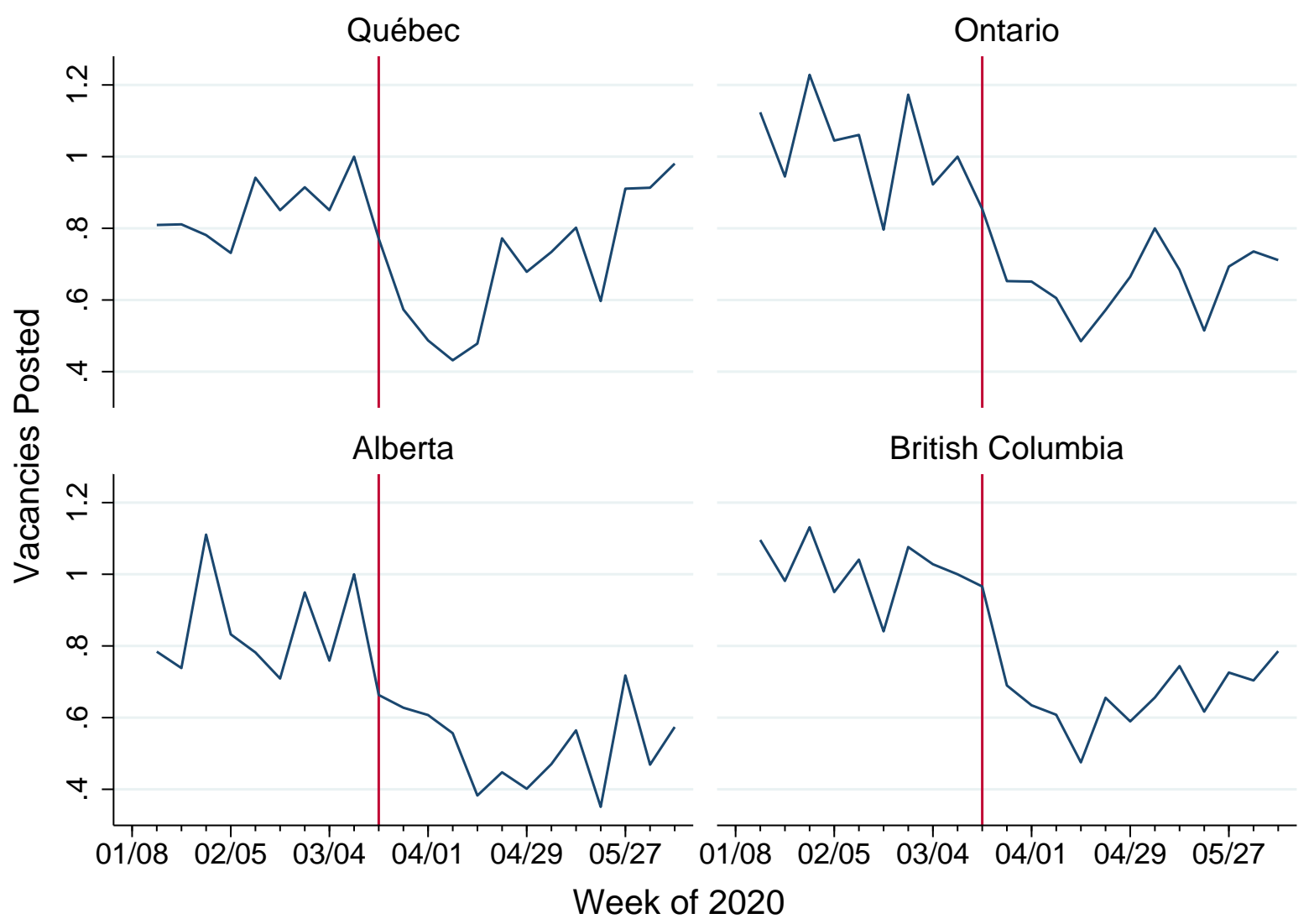

Note: Normalized against March 4-10.

from the absent from work analysis that employment itself may provide a misleading story. Again, the true fraction of those employed actually engaged in work may be overstated due to workers being absent but counted as employed. Another way to examine this issue is through hours of work. This would not only account for the effect of those absent from work, but will also capture any drop in hours for those present at work. In Figure 13, we see the decline in the hours worked conditional per employed worker was substantially more pronounced in Québec. However, again, we observe that for this measure as well that the recovery was relatively pronounced in Québec as compared to the other large provinces. 
Figure 12: Employment Rates across the 4 Largest Provinces

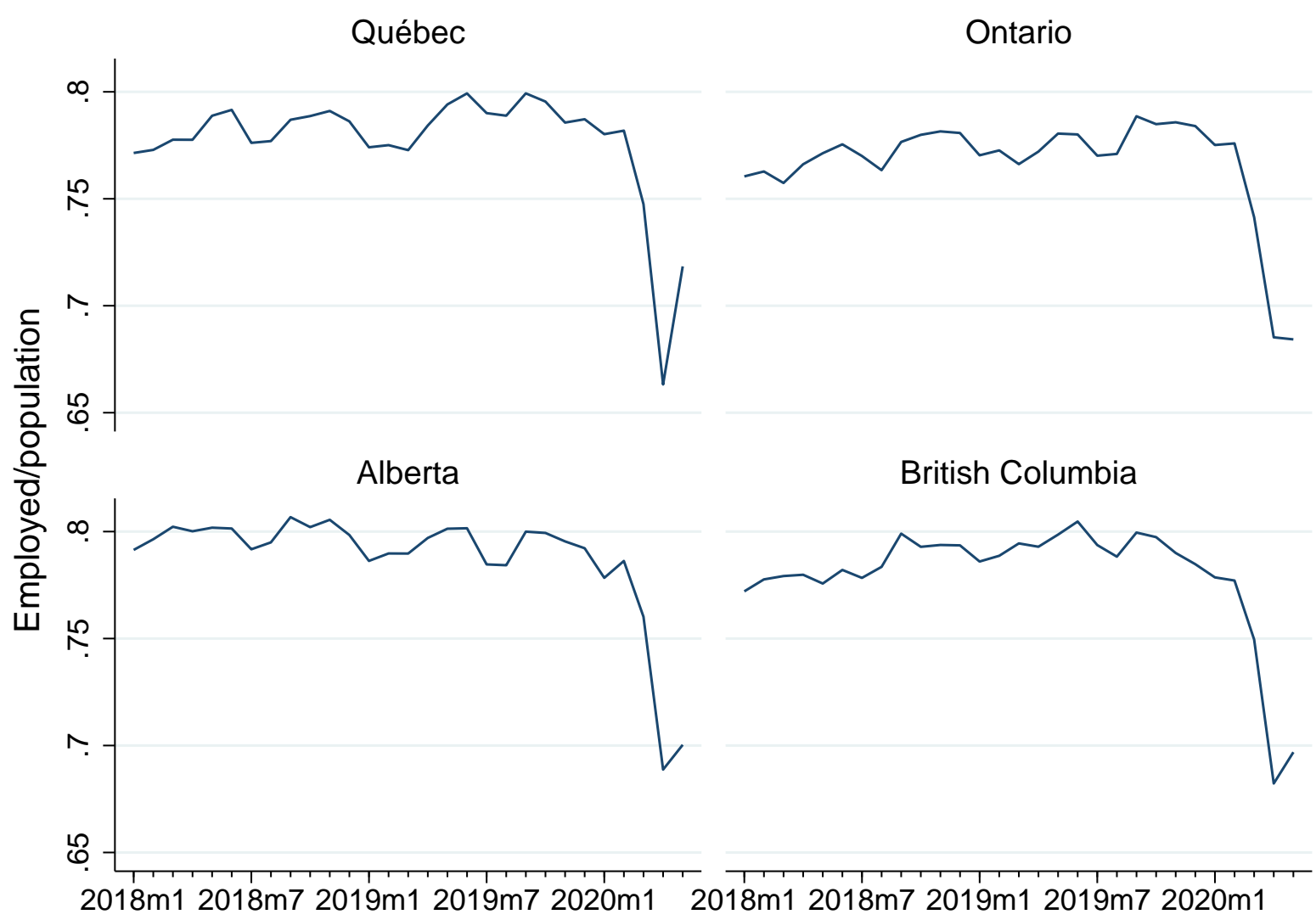

Note: Authors' calculations based on the LFS. Calculated as share of population ages 25-64.

Overall, we observe that the labour market in Québec seems to have rebounded more rapidly than in the Rest of Canada, even though across the country there is still a long way to go to return to a normal state of affairs.

\section{Conclusion}

The Canadian labour market has been hard hit by the COVID-19 crisis. The first half of 2020 saw unprecedented changes in both employment and unemployment, and changes in the 
Figure 13: Total hours/employed workers across the 4 largest Provinces

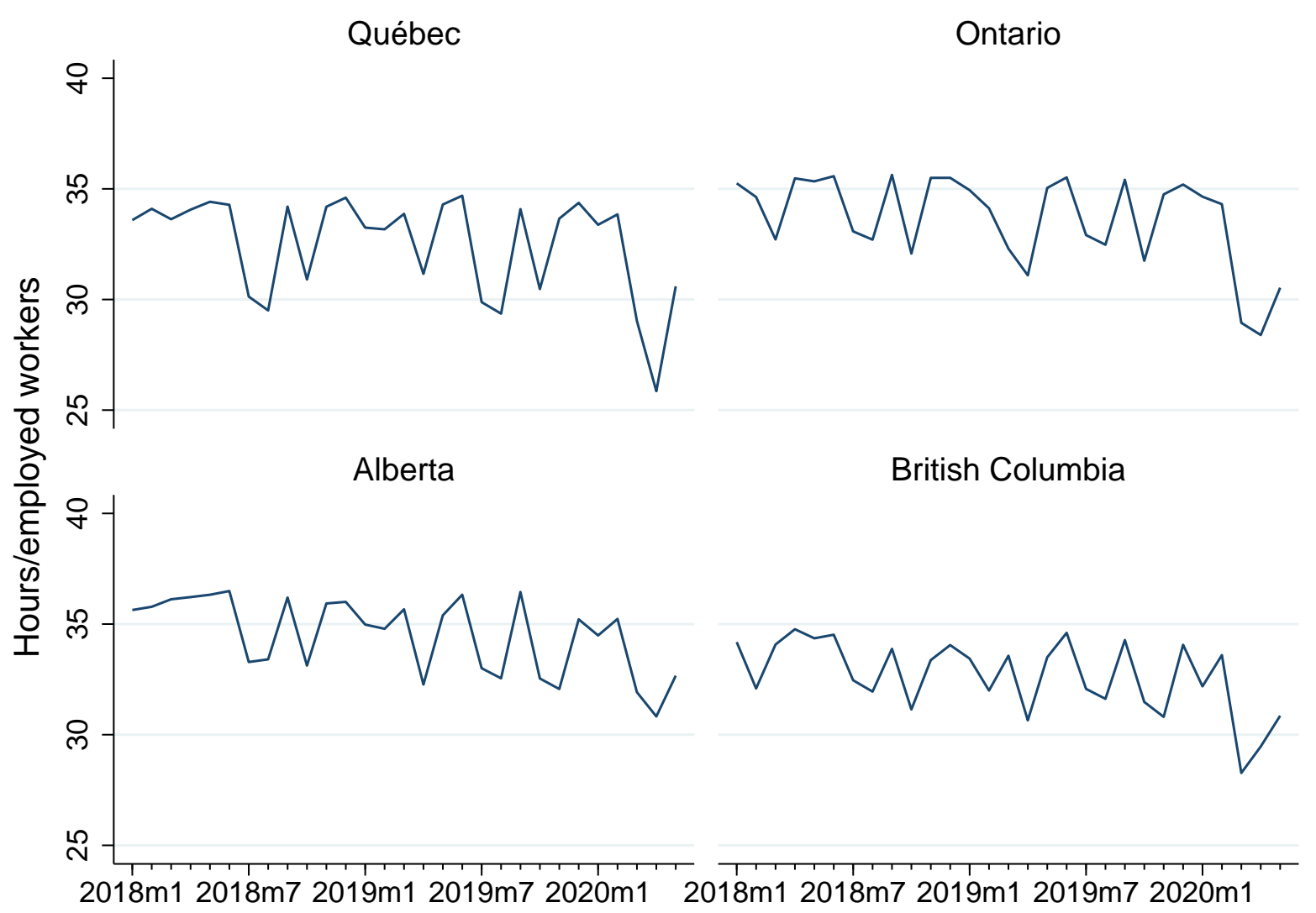

Note: Authors' calculations based on the LFS. Calculated as share of population ages 25-64.

underlying behaviours captured (or masked) by these magnitudes as traditionally measured. It also saw a $50 \%$ drop in labour demand, measured by vacancy postings, with some signs of a recovery in the past two months. There was important variation by occupation, particularly the ability to work from home, and by province. Going forward, we think three groups will be critical for how the labour market develops: the employed but absent from work, the unemployed on layoff but not searching for a job, and the marginally attached within NILF who want work but are not searching for a variety of reasons.

Finally, we comment on the data available in Canada for analysis of labour market developments in the current circumstances. The LFS is a key Canadian data source for timely 
information on the labour market impact of the ongoing COVID-19 crisis, with monthly data released only a few weeks after collection. Statistics Canada also responded to the pandemic by adding questions specific to COVID-19 to the LFS. However, to paint a more complete picture of how the economy is performing, it is imperative also to have timely and accurate vacancy data. Currently, the Job Vacancy and Wage Survey (JVWS), a key quarterly dataset for determining labour market demand in Canada, has a long lag before being released for analysis. At time of writing, the most current JVWS data are from the third quarter of 2019. 


\section{References}

Dingel, Jonathan I., and Brent Neiman (2020) 'How many jobs can be done at home?' Working Paper 26948, National Bureau of Economic Research, April

Jones, Stephen R.G., and W. Craig Riddell (1999) 'The measurement of unemployment: An empirical approach.' Econometrica 67(1), 147-162

_ (2019) 'Unemployment, marginal attachment and labor force participation in canada and the united states.' Journal of Labor Economics 37(S2), S399-S441

Kahn, Lisa B., Fabian Lange, and David G. Wiczer (2020) 'Labor demand in the time of COVID-19: Evidence from vacancy postings and UI claims.' Working Paper 27061, National Bureau of Economic Research, April

Lemieux, Thomas, Kevin Milligan, Tammy Schirle, and Mikal Skuterud (2020) 'Initial impacts of the COVID-19 pandemic on the Canadian labour market.' Working Paper 26, Canadian Labour Economics Forum, Spring/Summer 


\section{A Appendix}

\section{A.1 Supplemental Figures - Ability to Work from Home}

Figure A1 shows the distribution of the DN score in our data, binning occupations into 5 groups. Clearly, most occupations fall on the end-points of the distribution. In the paper, we categorize an occupation as an occupation that can be performed from home if its score exceeds 0.5. Not surprisingly, given the distribution shown in Figure A1, our estimates are not sensitive to varying the cutoff point of 0.5 .

We exclude health from this as demand for healthcare workers clearly was subject to different considerations during the crisis. We therefore obtain a classification scheme with

3 categories: 1. Health, 2. Wfh (work from home), and 3. Not-Wfh, where the latter two only apply to non-health occupations. 
Figure A1: Distribution of Ability to Work from Home

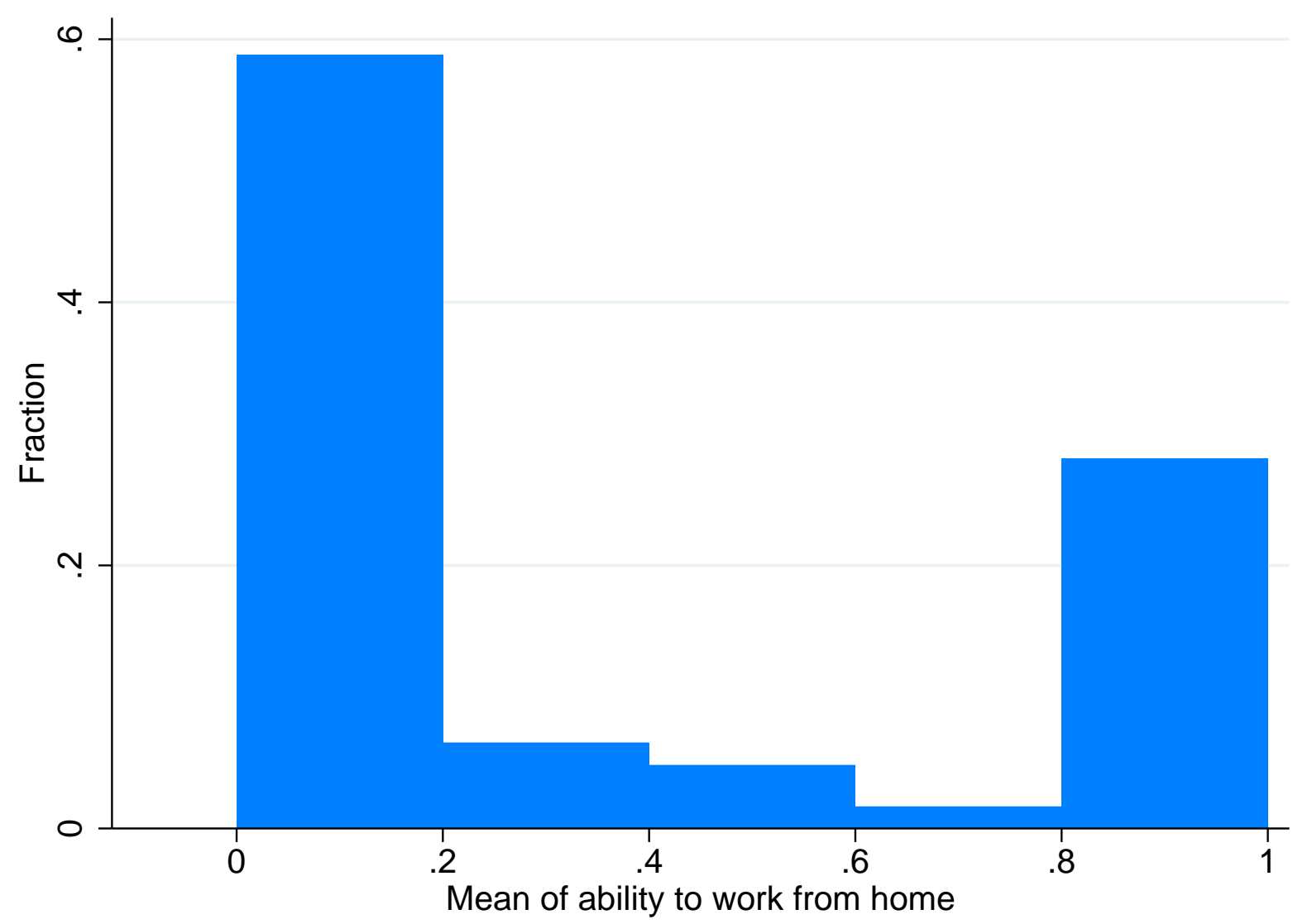

Note: The histogram plots 5-bin histogram of vacancies posted in the 3 weeks prior to March $15^{\text {th }}$ by the Dingel-Neiman score of ability to work from home. We mapped the Dingel-Neiman score onto the 4-digit NOC.

\section{A.2 Appendix: Indeed Vacancy Index}

Indeed collects data on vacancy postings on their job board as well as from other online sources. We received access to these data from Brendon Bernard, economist at Indeed Canada. Please refer to https://www.hiringlab.org/en-ca/ for more detail and analysis on this data.

In figure A2 we show the vacancy index for both Canada and the US indexed against the first full week of March. This index is constructed based on a dual averaging procedure 
to remove daily fluctuations. Indeed first averages new postings across the last 7 days and then averages the resulting number across the last seven days. Therefore the index is based on a weighted average across the last 14 days of postings. The weight on these 14 days is 1 for postings 14 days old and rises linearly to reach 7 for postings 7 days old. It then declines again linearly to reach 1 for the most recent postings.

The Indeed Index is therefore somewhat more backward looking than the vacancy index we show in Section 2.

Figure A2: Indeed Vacancy Index: Febr 4-June 2

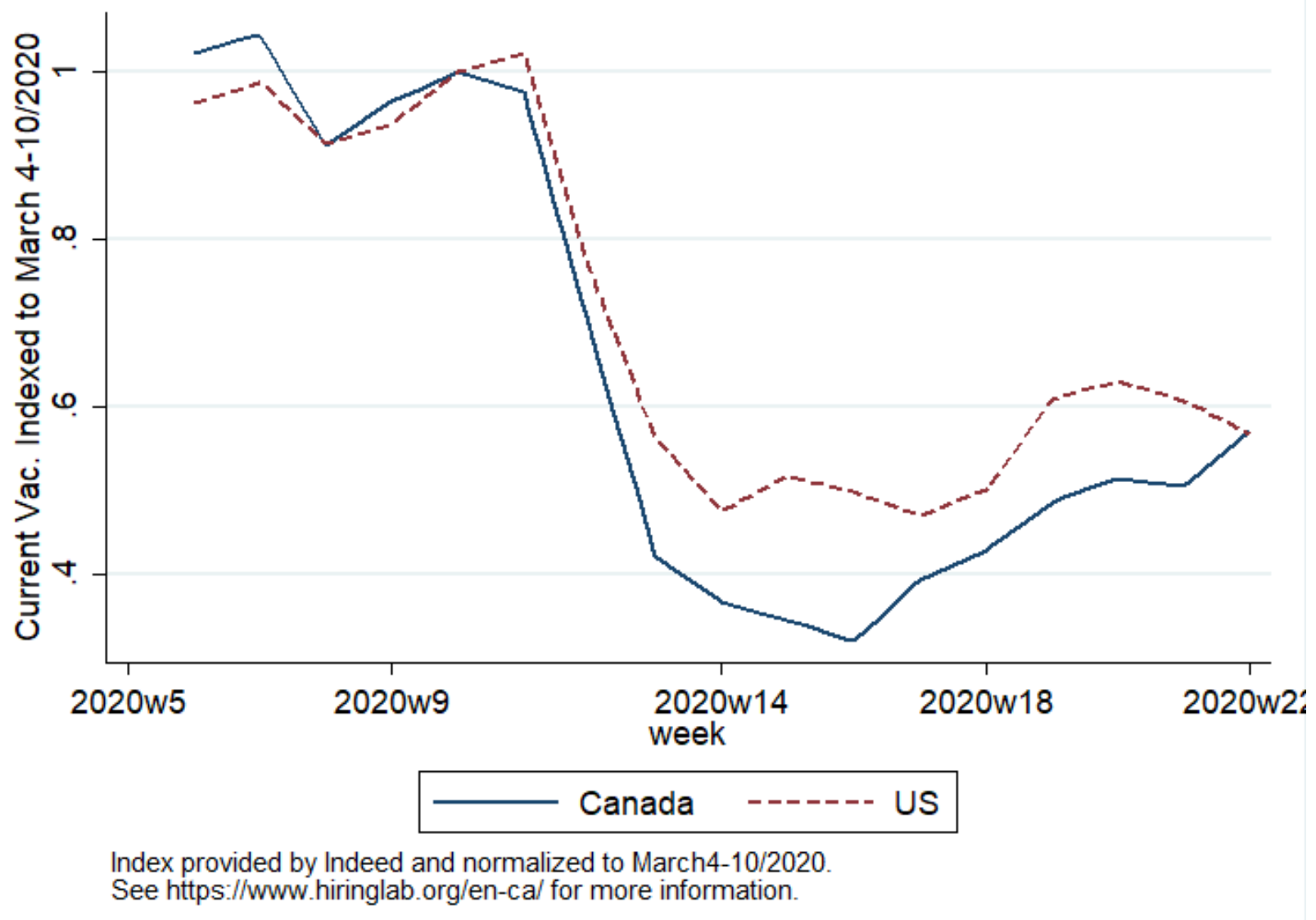

Note: Indeed Vacancy Index provide by Indeed Canada. Please see https://www.hiringlab.org/en-ca/ 
Figure A3: Paid for time off, full-week absents for labour related reasons

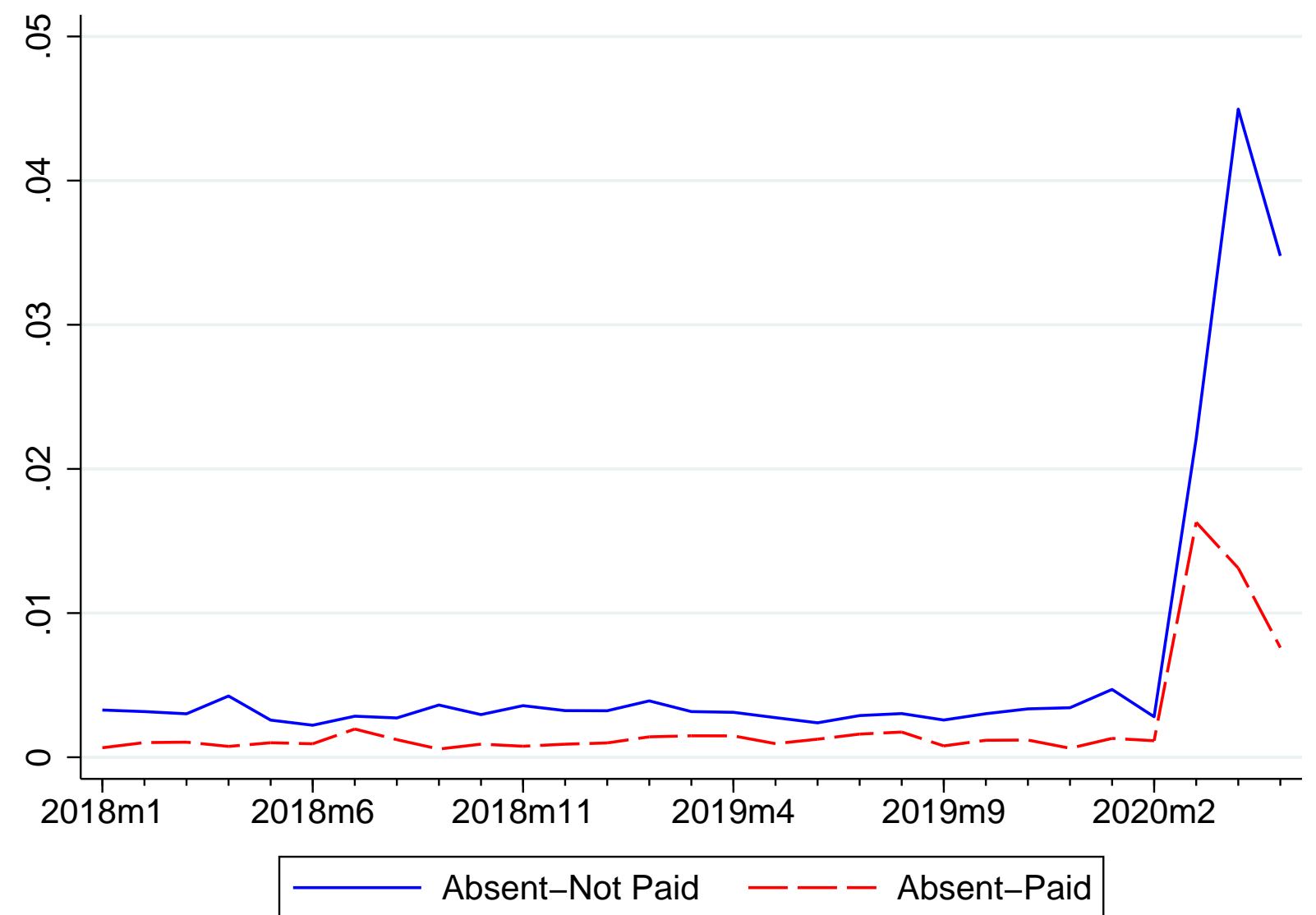

Note: Authors' calculations based on the LFS. The paid for time off information is not available for self-employed unincorporated workers. Absents restricted to "Other" reason which includes: no work available, seasonal business, strike/lockout, and other related reasons. Sample restricted to individuals aged 25-64. 